\title{
Reduced CTLA-4 protein and messenger RNA expression in umbilical cord blood $\mathrm{T}$ lymphocytes
}

\author{
Robin E. Miller ${ }^{\mathrm{a}}$, John D. Fayen ${ }^{\mathrm{b}}$, Shaden F. Mohammad ${ }^{\mathrm{c}}$, \\ Kevin Stein ${ }^{\mathrm{c}}$, Suzanne Kadereit ${ }^{\mathrm{c}}$, Kathleen Daum Woods ${ }^{\mathrm{c}}$, R. Michael Sramkoski ${ }^{\mathrm{c}}$, \\ James W. Jacobberger ${ }^{c}$, Dennis Templeton ${ }^{\mathrm{b}}$, Susan B. Shurin ${ }^{\mathrm{a}}$, and Mary J. Laughlin ${ }^{\mathrm{c}}$ \\ Departments of a Pediatrics, ${ }^{\mathrm{b}}$ Pathology, and ${ }^{\mathrm{c}}$ Medicine, \\ University Hospitals Ireland Comprehensive Cancer Center, Case Western Reserve University, Cleveland, Ohio, USA
}

\begin{abstract}
Objective. A favorable incidence and severity of graft-vs-host disease is observed in patients transplanted with banked, unrelated, HLA-mismatched umbilical cord blood (UCB) grafts, while the incidence of malignant relapse remains low. CTLA-4 mediates negative T-cell signaling and may contribute to the development of allogeneic tolerance. In this study, we compared protein and mRNA expression of CTLA-4 in stimulated UCB and adult peripheral blood T cells.

Materials and Methods. T cells were isolated from UCB and adult peripheral blood and stimulated with anti-CD3 and anti-CD28 monoclonal antibodies. Cells were immunostained and analyzed by flow cytometry for both surface and intracellular expression of CTLA-4 in the presence and absence of cyclosporin A, and kinetics of CTLA-4 expression compared. CTLA-4 mRNA expression was measured using quantitative real-time polymerase chain reaction. NFAT1 protein levels were measured by Western blot analysis.

Results. These studies demonstrate reduced surface and intracellular expression of CTLA-4 in stimulated UCB T cells compared to adult controls. Furthermore, reduced CTLA-4 protein expression in UCB $T$ cells was noted to be in part transcriptionally regulated, as CTLA-4 mRNA levels also were significantly lower. Reduced CLTA-4 expression by UCB T cells followed the kinetics of delayed and reduced expression of the transcription factor NFAT1 by UCB T lymphocytes during primary stimulation. Moreover, cyclosporin A, which is known to modulate NFAT activation, reduced CTLA-4 protein expression in adult and UCB T cells.

Conclusion. Reduced expression of the key regulatory proteins CTLA-4 and NFAT-1 may contribute to favorable UCB T lymphocyte allogeneic responses.

for Experimental Hematology.
\end{abstract}

Allogeneic transplantation using unrelated donors is limited by graft-vs-host disease (GVHD) mediated by donor T cells recognizing major and minor histocompatibility antigens on recipient antigen-presenting cells [1,2]. Clinical efforts are currently underway to ameliorate GVHD, while preserving the T-cell repertoire to fight infection and disease relapse. The use of banked unrelated umbilical cord blood (UCB) for allogeneic transplant is a promising approach because the incidence and severity of GVHD is favorable compared

Offprint requests to: Mary J. Laughlin, M.D., Allogeneic Transplant Program, Case Western Reserve University, University Hospitals Ireland Comprehensive Cancer Center, 11100 Euclid Avenue, Cleveland, OH 44106-5065; E-mail: mj113@po.cwru.edu with that in recipients of matched unrelated grafts from adult donors, despite infusion of HLA disparate grafts [3-9]. Graft-vs-leukemia effects also are mediated by $\mathrm{T}$ cells, as recipients of T-cell-depleted allografts suffer increased rates of relapse [10-12]. Interestingly, studies thus far have not demonstrated an increase in the incidence of relapse following unrelated UCB stem cell transplant [8,9], suggesting that the graft-vs-leukemia effect of these grafts remains intact despite the low incidence of GVHD.

Efficient T-cell activation requires primary T-cell receptor stimulation and a second costimulatory signal delivered via CD28. CD28 engagement by the B7 molecules (B7-1 and B7-2) expressed on antigen-presenting cells, in conjunction with $\mathrm{T}$-cell receptor-generated signals, results in enhanced T-cell proliferation and cytokine production $[13,14]$. 
Similar CD28 surface expression and costimulatory function have been demonstrated in UCB and adult T cells $[15,16]$. CTLA-4, which is expressed exclusively on activated $\mathrm{T}$ cells, binds both B7-1 and B7-2 with a 10-fold to 20-fold higher affinity [17-19], thereby competing with CD28 for its activating ligand. Evidence from CTLA-4 gene-deleted mice as well as antibody-blocking studies clearly indicate that CTLA-4 mediates negative T-cell signaling [20,21].

Many studies support a critical role for CTLA-4 in the regulation of tolerance $[19,20,22]$. Compelling evidence for this is the dramatic, rapidly fatal lymphoproliferative disorder observed in CTLA-4 gene-deleted mice [21,23]. Additional support is derived from murine models of autoimmunity, including experimental autoimmune encephalitis and autoimmune diabetes, in which CTLA-4 blockade promotes disease progression [24-27]. In humans, a base-exchange polymorphism within the gene encoding CTLA-4 is linked with the development of several autoimmune disorders [19,28-31]. The CD28/CTLA-4/B7 pathway also has been implicated in the pathogenesis of GVHD. Murine transplant studies clearly indicate that CD28 costimulation exacerbates GVHD while CTLA-4 engagement can attenuate its severity [32-34].

In addition to its role in allograft tolerance, CTLA-4 blockade enhances antitumor immune responses in mice [3539]. Leach et al. [40] demonstrated that a CTLA-4-blocking antibody given to mice injected with tumor cells inhibited tumor growth, even when the tumor cells did not express B7. When subsequently reinjected with tumor cells, these mice were protected against tumor regrowth, demonstrating maintained immunologic memory after CTLA-4 blockade.

We compared CTLA-4 expression by activated UCB and adult peripheral blood $\mathrm{T}$ cells during primary stimulation. We observed that activated UCB T lymphocytes expressed significantly less CTLA-4, including both cell surface and total protein expression, as well as less CTLA-4 mRNA upon stimulation compared with adult controls.

\section{Materials and methods}

Cells

After obtaining informed consent, human UCB was collected into sterile bags containing citrate dextrose (Allegiance, Deerfield, IL, USA) after delivery of full-term neonates of healthy mothers and processed as described. Peripheral blood mononuclear cells were enriched for $\mathrm{T}$ cells by negative selection using the monoclonal antibodies (mAbs) anti-CD11b, anti-CD19, anti-CD16, and antiCD56 (Pharmingen, San Diego, CA, USA), followed by antiimmunoglobulin $\mathrm{G}$ magnetic bead depletion (Dynal, Lake Success, NY, USA). This purification method results in greater than $90 \%$ purity of $\mathrm{CD}^{+} \mathrm{T}$ cells when assessed by flow cytometry, as previously described [41].

\section{Cell culture and stimulation}

T cells either were cultured in RPMI-1640 (Gibco BRL, Gaithersburg, MD, USA) with $10 \%$ fetal bovine serum (Gibco BRL) and antibiotic/antimycotic (Sigma, St. Louis, MO, USA) in 48-well plates at a density of $2 \times 10^{6}$ cells $/ \mathrm{mL}$ or were stimulated with plate-bound anti-CD3 mAb (Hit3a; Pharmingen) at $1 \mu \mathrm{g} / \mathrm{mL}$ and soluble anti-CD28 mAb (CD28.2; Pharmingen) at $5 \mu \mathrm{g} / \mathrm{mL}$ for the indicated time period. Where indicated, $1 \mu \mathrm{g} / \mathrm{mL}$ CsA (Sigma) was added at the time of plating.

Flow cytometry

Cells were immunostained with panels of fluorochrome-conjugated mAbs, as well as isotype-matched controls. Anti-CD45RA and anti-CD45RO were purchased from Caltag (Burlingame, CA, USA). Anti-CD3, anti-CD69, and CTLA-4 were purchased from Becton-Dickinson (San Jose, CA, USA). For intracellular staining, lymphocytes were permeabilized with FACS Permeabilizing Solution (Becton-Dickinson) prior to staining. Data were acquired using an Elite ESP flow cytometer (Coulter, Miami, FL, USA). Compensation and analysis were performed using WinList software (Verity Software House, Topsham, MN, USA).

\section{Real-time polymerase chain reaction}

To generate template DNA for the CTLA- 4 standard curve, the plasmid pCTLA-4(h) Ig/REP7 $\beta$ [42] was generously provided by M. Tykocinski (Department of Pathology, University of Pennsylvania). The sequence encoding the two extracellular domains of hCTLA-4 was liberated by Hind III digestion, and the resulting fragment was gel purified. To generate template DNA for the actin standard curve, I.M.A.G.E. CloneID 61151 in pBluescript SK was purchased from American Type Culture Collection (Manassas, VA, USA). The coding sequence was liberated by digestion with EcoRI/XhoI, followed by gel purification.

Primer pairs were selected with the assistance of Oligo 6.4 (Molecular Biology Insights, Cascade, CO, USA). Oligonucleotide primers for polymerase chain reaction (PCR) were designed to cross at least one intron and were purchased from Sigma-Genosys (Woodlands, TX, USA). The CTLA-4 primer sequences used were 5'-CACAAGGCTCAGCTGAACCT-3' and 5'-AGGTGCCCGTGCAGATGGAA-3' for an amplicon length of $294 \mathrm{bp}$. The actin primer sequences used were 5'-CGGGAAATCGTGCGTGACAT-3' and 5'-CTAGAAGCATTTGCGGTGGA-3' for an amplicon length of $492 \mathrm{bp}$. Primers were used at a concentration of $1 \mu \mathrm{M}$ for real-time PCR.

Resting $\mathrm{T}$ cells and $\mathrm{T}$ cells cultured for 22 hours with platebound anti-CD3 and soluble anti-CD28 were harvested, and total RNA was isolated by acid phenol extraction [43]. Total RNA was reverse transcribed with oligo-dT using Superscript II (Gibco BRL) following the manufacturer's instructions. Resulting cDNAs were subjected to quantitative real-time PCR using a Roche Light Cycler (Roche, Indianapolis, IN, USA). Double-stranded product was detected using SYBR Green I (Roche) following the manufacturer's instructions. Products of real-time PCR were run on agarose gels to assess amplicon size, and representative amplified product was sequenced for confirmation.

\section{Western blot analysis}

$\mathrm{T}$ cells were lysed and analyzed for NFAT1 expression as previously described [41]. Band intensities were quantified by densitometry scanning on Sci Scan 5000 (U.S. Biochemical, Cleveland, $\mathrm{OH}, \mathrm{USA}$ ) and normalized for loading with the actin band.

\section{Proliferation assays}

A total of $0.2 \times 10^{6} \mathrm{~T}$ cells were plated in triplicate and pulsed with $1 \mu \mathrm{Ci}$ of ${ }^{3} \mathrm{H}$-thymidine (Amersham, Buckinghamshire, UK), 
cultured for 24 hours in 96-well flat-bottomed plates, and harvested onto glass fiber filtermats (Wallac Oy, Turku, Finland) using a Harvester 96 (Tomtec Inc., Hamden, CT, USA). Incorporated ${ }^{3} \mathrm{H}$-thymidine was measured using a MicroBeta Trilux scintillation counter (EG\&G Wallac, Turku, Finland).

\section{Statistical analysis}

Values are given as mean \pm SEM. Statistical significance was determined between the indicated values by paired $t$-test.

\section{Results}

\section{Induction of cell surface and total cellular}

CTLA-4 expression is reduced in UCB T cells

We used flow cytometry to compare induction of CTLA-4 expression by gated $\mathrm{CD}^{+} \mathrm{UCB}$ and adult $\mathrm{T}$ cells after 48 hours of primary stimulation. Although expression of the activation marker CD69 was similar in activated UCB and adult $\mathrm{T}$ cells (data not shown), fewer $\mathrm{UCB} \mathrm{CD3}^{+} \mathrm{T}$ cells were induced to express CTLA-4 than adult: $6.8 \% \pm 1.3 \%$ $\mathrm{UCB}$ vs $21.4 \% \pm 2.9 \%$ adult $\mathrm{CD}^{+} \mathrm{T}$ cells (Fig. 1A). Moreover, surface CTLA-4 expression was reduced in both $\mathrm{CD}^{+}{ }^{+} \mathrm{CD}^{+}{ }^{+}$and $\mathrm{CD}^{+}{ }^{+} \mathrm{CD}^{+}{ }^{+} \mathrm{T}$-cell subpopulations in $\mathrm{UCB}$ compared to adult (data not shown). Surface expression of CTLA-4 on stimulated $\mathrm{UCB} \mathrm{CD}^{+} \mathrm{CD}_{45 \mathrm{RA}^{+}}$and $\mathrm{CD}^{+}$ $\mathrm{CD}^{2} \mathrm{RO}^{+} \mathrm{T}$ cell subsets also were decreased compared to adult: $6.6 \% \pm 1.4 \%$ in UCB vs $10.8 \% \pm 1.9 \%$ in adult and $7.2 \% \pm 2.4 \%$ in UCB vs $19.4 \% \pm 2.9 \%$ in adult, respectively (Fig. 1B and C). Reduced CTLA-4 levels therefore reflects a deficiency in expression rather than a simple numerical predominance of the $\mathrm{CD}^{+}{ }^{+} \mathrm{CD} 45 \mathrm{RA}^{+}$population in UCB T cells.

Only a small proportion of CTLA-4 is expressed on the cell surface, with substantial amounts located in subcellular clathrin-coated vesicles [44,45]. Intracellular staining for CTLA-4 was performed to assess total cellular expression of CTLA-4, which was noted to be similarly decreased, with $47.6 \% \pm 2.1 \%$ adult compared to $22.9 \% \pm 3.7 \%$ $\mathrm{UCB} \mathrm{CD}^{+} \mathrm{T}$ cells expressing CTLA-4 (Fig. 1D). Mean fluorescence intensity of CTLA-4 staining also was reduced in UCB T cells compared to adult (Table 1).
To determine if the reduced CTLA- 4 expression by UCB $\mathrm{CD}^{+} \mathrm{T}$ cells reflects a difference in the timing of CTLA-4 induction between cord and adult $\mathrm{T}$ cells, we examined the kinetics of CTLA-4 induction during primary T-cell stimulation. UCB and adult T cells were stimulated with antiCD3 and anti-CD28 for 96 hours, and both surface and intracellular staining analyses were performed at 24-hour increments. In UCB T cells, CTLA-4 induction was severely impaired at early time points (Fig. 2). Proportion of T cells expressing CTLA-4 in UCB was less than half that measured in adults at the previously described 48-hour plateau of CLTA-4 induction [46]. Although UCB T-cell surface CTLA-4 remained low up to 96 hours, intracellular CTLA-4 rose in UCB T cells and approached adult levels by 72 hours (Fig. 2).

\section{CTLA-4 mRNA expression is reduced in stimulated UCB $T$ cells}

With observations of surface and intracellular reduced CTLA-4 protein expression in stimulated UCB T cells at early time points, we hypothesized that reduced CTLA-4 protein expression might be caused by reduced CTLA-4 mRNA expression in UCB T cells. Real-time PCR analysis was performed to compare CTLA-4 mRNA expression in UCB versus adult T cells, after stimulation with plate-bound anti-CD3 and soluble anti-CD28 for 22 hours. CTLA-4 mRNA expression in unstimulated cells was negligible for both UCB and adult (data not shown). However, after 22 hours of stimulation, CTLA-4 message levels were significantly lower in UCB T cells compared to adult T cells, with levels in UCB averaging only 49\% ( \pm 9.2 SEM, $\mathrm{n}=9 ; p=$ 0.015 ) of that measured concomitantly in stimulated adult $\mathrm{T}$ cells. Thus, the reduced expression of CTLA-4 in UCB T cells at early time points during primary stimulation appears to result from reduced expression of CTLA-4 mRNA.

\section{UCB T cells demonstrate an} increased rate of autoproliferation

$\mathrm{T}$ cells isolated from CTLA-4 gene deleted mice demonstrate markedly increased proliferation in the absence of any

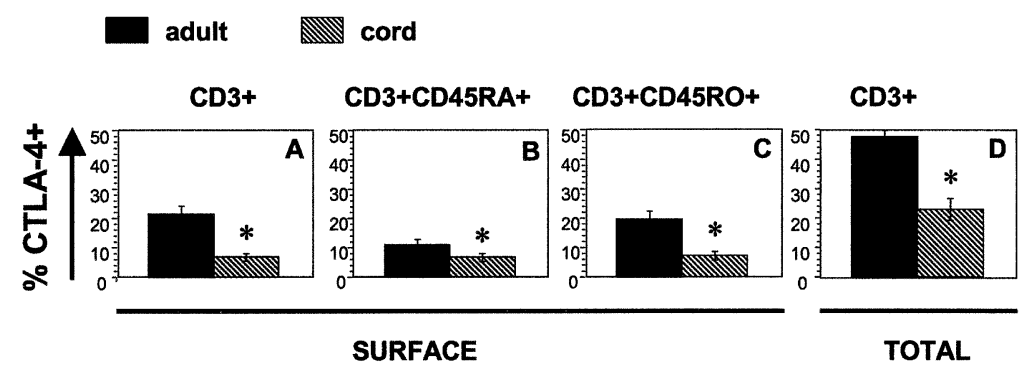

Figure 1. Reduced percentages of CTLA-4-expressing T cells in UCB during primary stimulation. UCB and adult T cells were stimulated for 48 hours with plate-bound anti-CD3 and soluble anti-CD28, and analyzed by flow cytometry. (A) CTLA-4 expression on the surface of gated CD3 ${ }^{+}$cells. $\mathrm{n}=12 .{ }^{*} p=$ 0.0001. (B) CTLA-4 expression on the surface of gated CD3 ${ }^{+} / \mathrm{CD} 45 \mathrm{RA}^{+}$cells. $\mathrm{n}=8 .{ }^{*} p=0.0086$. (C) CTLA-4 expression on the surface of gated $\mathrm{CD} 3{ }^{+} /$ CD45RO ${ }^{+}$cells. $\mathrm{n}=8 .{ }^{*} p=0.0064$. (D) CTLA-4 expression in gated, permeabilized CD3 ${ }^{+}$cells. $\mathrm{n}=6 .{ }^{*} p=0.0009$. 
Table 1. Reduced fluorescence intensity of CTLA-4 expression in gated UCB T cells

\begin{tabular}{|c|c|c|c|c|c|c|c|c|c|c|c|c|}
\hline \multirow[b]{2}{*}{ Surface } & \multicolumn{10}{|c|}{$\mathrm{n}$} & \multirow[b]{2}{*}{ Mean } & \multirow[b]{2}{*}{ SEM } \\
\hline & 1 & 2 & 3 & 4 & 5 & 6 & 7 & 8 & 9 & 10 & & \\
\hline Cord & 26.6 & 23.3 & 16.2 & 19.8 & 14.2 & 31.9 & 27.9 & 37.0 & 38.3 & 13.5 & 24.9 & 2.9 \\
\hline Adult & 60.6 & 41.7 & 32.0 & 38.3 & 21.2 & 57.7 & 52.8 & 55.7 & 52.0 & 28.3 & $44.0^{*}$ & 4.3 \\
\hline & & & $\mathrm{n}$ & & & & & & & & & \\
\hline Intracellular & 1 & 2 & 3 & 4 & 5 & Mean & SEM & & & & & \\
\hline Cord & 24.6 & 36.8 & 23.2 & 19.4 & 30.1 & 26.8 & 3.0 & & & & & \\
\hline Adult & 79.5 & 60.2 & 50.5 & 44.5 & 81.3 & $63.2 *$ & 7.5 & & & & & \\
\hline
\end{tabular}

T cells were purified and stimulated for 48 hours with plate-bound CD3 and soluble CD28 and CTLA- 4 expression analyzed by flow cytometry. Fluorescence intensity of CTLA-4 surface and intracellular staining are expressed as mean channel fluorescence.

$* p<0.01$, paired $t$-test, comparing cord and adult.

external stimulation $[21,47]$. We therefore measured proliferation in the absence of stimulation in UCB T cells and found that ${ }^{3} \mathrm{H}$-thymidine incorporation by UCB T cells, after 24 hours of culture, was significantly greater than that of adult T cells: $2870 \pm 603 \mathrm{cpm}$ for UCB vs $225 \pm 47 \mathrm{cpm}$ for adult T cells (Fig. 3). Thus, reduced CTLA-4 expression in UCB T cells is accompanied by an increased rate of autoproliferation.

\section{CTLA-4 protein expression in both}

$U C B$ and adult T cells is CsA sensitive

Given the presence of NFAT binding sites within the CTLA-4 promoter region [48], we investigated the susceptibility of CTLA-4 expression to inhibition by a CsA, a known inhibitor of NFAT activation. Addition of CsA to cultures during primary stimulation significantly inhibited increase of total CTLA-4 protein expression in both UCB and adult $\mathrm{T}$ cells $(p=0.0039)$, with $54.6 \% \pm 18 \%$ inhibition in adult $\mathrm{T}$ cells vs $58.6 \% \pm 9.4 \%$ in UCB (Fig. 4 ).

Concomitant measurement of NFAT1 protein expression by Western blot analysis showed reduced and delayed NFAT1 protein expression by UCB T cells compared to adult at all time points (Fig. 5). Notably, induction of
CTLA-4 protein expression followed NFAT1 induction in UCB by approximately 24 hours.

\section{Discussion}

Although the precise mechanisms underlying the favorable incidence of GVHD in UCB recipients have not yet been established, certain unique immunologic features render UCB optimal for use in the allogeneic transplant setting. Activated UCB lymphocytes produce lower amounts of several cytokines known to contribute to clinical GVHD, including interferon- $\gamma$ (IFN- $\gamma$ ), tumor necrosis factor- $\alpha$ (TNF- $\alpha)$, and interleukin-2, demonstrate reduced generation of specific cytotoxic effectors, and, upon restimulation, a state of proliferative unresponsiveness is induced [49-51]. Furthermore, reduced NFAT1 protein expression by UCB T cells may be one mechanism underlying the blunted allogeneic responses observed in UCB T cells [41].

Our studies demonstrate reduced surface and intracellular CTLA-4 expression in UCB T cells compared to adult controls. Interestingly, reduced and delayed CTLA-4 expression in UCB T cells followed reduced and delayed expression of NFAT1 in UCB by approximately 24 hours. We

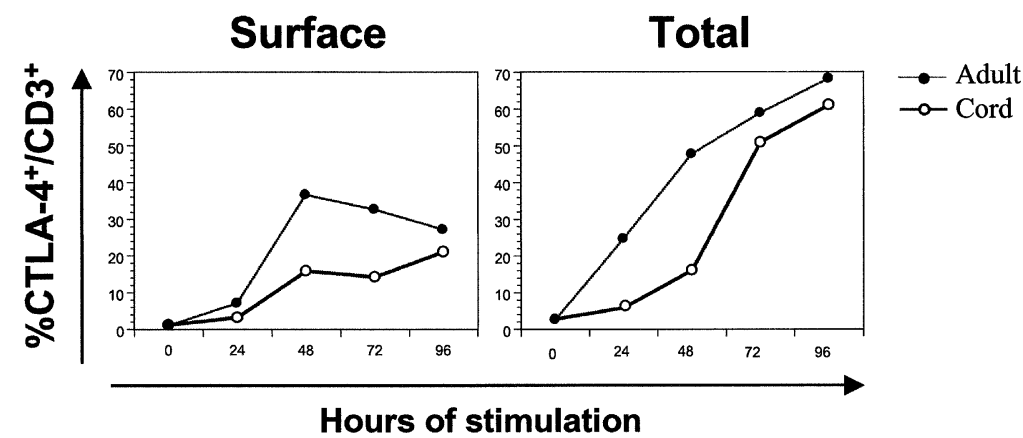

Figure 2. Kinetics of CTLA-4 expression in UCB compared to adult T cells. Adult and UCB T cells were stimulated with anti-CD3 and anti-CD28 mAbs for $24,48,72$, and 96 hours, and analyzed by flow cytometry on gated on $\mathrm{CD}^{+}$population. For total staining, cells were permeabilized prior to staining with CTLA-4 mAb. Shown is one experiment, representative of three identical experiments, comparing each one UCB with one adult control. 


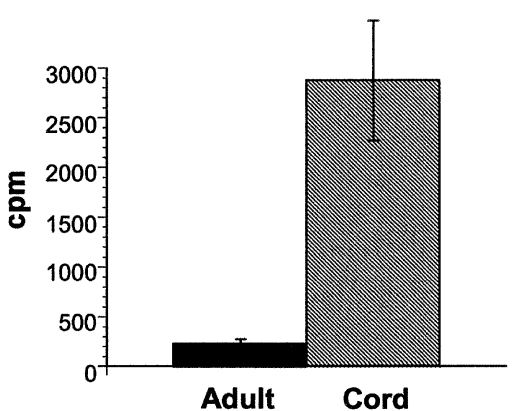

Figure 3. UCB T cells demonstrate greater autoproliferation compared to adult. UCB and adult T cells were plated in triplicate, without stimulation, at $0.2 \times 10^{6} /$ well in 96 -well flat-bottom plates in RPMI with $10 \%$ fetal calf serum. ${ }^{3} \mathrm{H}$-thymidine $1 \mu \mathrm{Ci}$ was added at plating, and cells were harvested after 24 hours of culture and incorporated radioactivity counted. Represented are mean values \pm SEM of three identical experiments, comparing each one UCB with one adult control.

also observed reduced CTLA-4 mRNA expression, suggestive of reduced transcriptional activation. CTLA-4 gene activation may depend upon an NFAT binding site within the CTLA-4 promoter [48,52]. Accordingly, CsA, a well-described inhibitor of NFAT, has been shown to inhibit CTLA-4 mRNA expression [53]. Reduced CTLA-4 expression also was observed in our studies in the presence of CsA, with equal inhibition noted in UCB and adult T cells (Fig. 4).

We also showed that UCB T cells autoproliferate more rapidly than adult $\mathrm{T}$ cells when cultured in the absence of

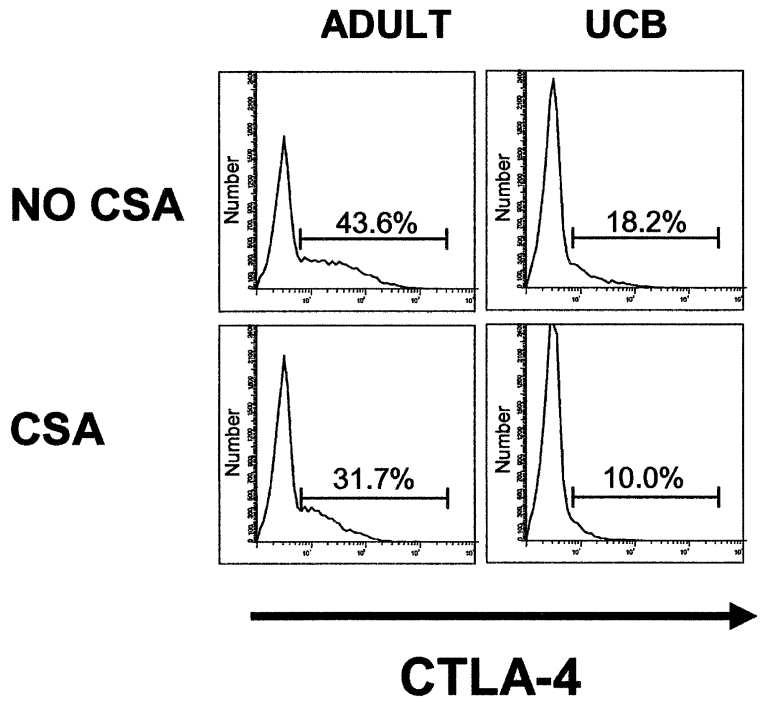

Figure 4. CsA inhibits CTLA-4 protein expression in both UCB and adult $\mathrm{CD}^{+} \mathrm{T}$ cells. UCB and adult $\mathrm{T}$ cell were cultured for 48 hours with anti$\mathrm{CD} 3$ and anti-CD28 stimulation, in the presence or absence of $1 \mu \mathrm{g} / \mathrm{mL}$ CsA, followed by intracellular staining and analysis by flow cytometry on gated $\mathrm{CD}^{+}$cell populations. Histograms depict CTLA- 4 expression by adult and UCB T cells in the presence or absence of CsA. Shown is a representative of three similar experiments, comparing each one UCB with one adult control.
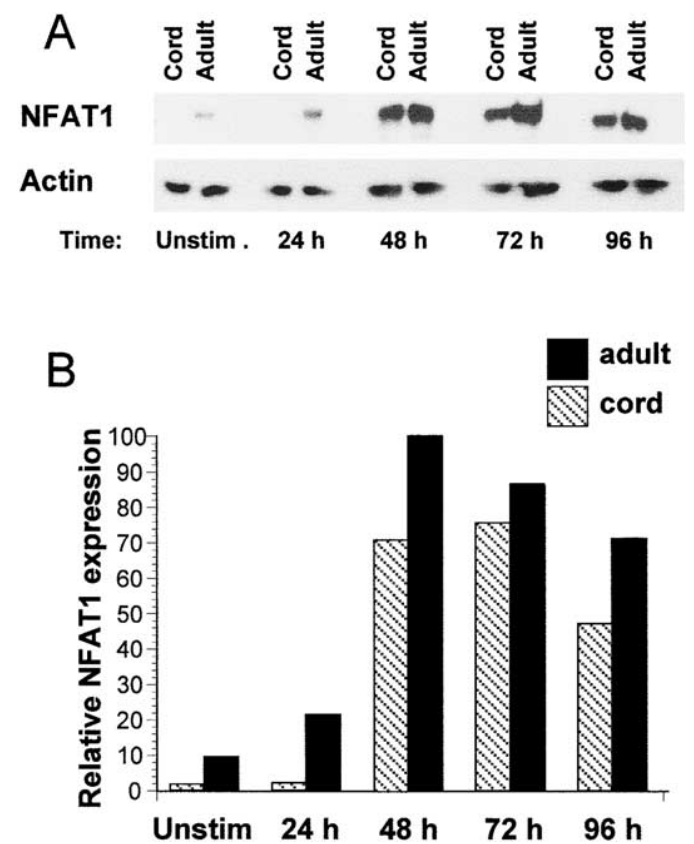

Figure 5. UCB $\mathrm{T}$ cells stimulated with anti-CD 3 and anti-CD28 express reduced NFAT1 protein compared to adult T cells. (A) Adult and UCB T cells were stimulated with anti-CD3 and anti-CD28. At hour 0 (unstim), $24,48,72$, and 96 hours of stimulation protein extracts were made and analyzed by Western blot with anti-NFAT1 and anti- $\beta$-actin antibodies. (B) Graphic representation of the blot shown in panel A showing quantification of relative NFAT1 protein expression. Gel loading was normalized for each lane with the actin band, and the intensity of each NFAT1 band was calculated as relative percentage of the most intense NFAT1 band. The most intense band was set arbitrarily at $100 \%$ and relative percentages calculated. Shown is a representative of three similar experiments, comparing each one UCB with one adult control.

external stimulation. Interestingly, the degree of autoproliferation by UCB T cells (Fig. 3) mirrored that observed in T cells from CTLA-4 gene-deleted mice [21,47], suggesting that deficient CTLA-4 may result in an increased baseline activation status in the neonatal cells.

Animal studies have established that $\mathrm{T}$ cell costimulatory function is important in mediating GVHD [33] and that costimulatory blockade can both reduce GVHD [34] and promote engraftment [54]. Blockade of CD28/B7-mediated costimulation has been brought to the clinical setting in a recent human trial in which donor bone marrow was cocultured ex vivo with irradiated recipient $\mathrm{T}$ cells in the presence of CTLA-4 immunoglobulin. This graft manipulation resulted in significantly reduced donor T-cell responsiveness to recipient alloantigens, as well as reduced GVHD, in patients transplanted with HLA haplo-mismatched donors [55]. Thus, costimulatory blockade promises to be a useful tool to facilitate engraftment and reduce GVHD.

Observing reduced CTLA-4 expression in UCB T cells upon primary stimulation, one would expect increased GVHD after UCB T-cell transplantation. However, this is not the case. Several reports point toward a role for CTLA-4 
in cytokine regulation, including IFN- $\gamma$ production $[23,56$, 57]. As UCB T lymphocytes are severely impaired in IFN- $\gamma$ and TNF- $\alpha$ production after primary and secondary stimulation [58], IFN- $\gamma$ and TNF- $\alpha$ production would not be expected to increase in UCB T cells, due to lack of downmodulation by CTLA-4 signaling. Moreover, in the murine model, absence/blockade of CTLA-4 in vitro and in vivo has been shown to result in bias toward a Th2 phenotype $[20,47]$. Also, the observed higher rates of activation-induced cell death observed in UCB T lymphocytes after secondary stimulation [58] may be a contributing factor in the observed clinical observations of reduced GVHD after UCB transplant. Therefore, reduced expression of the key regulatory proteins CTLA-4 and NFAT1 may contribute to clinical observations of favorable UCB T-lymphocyte allogeneic responses.

\section{Acknowledgments}

R.E.M. is supported by grant CA76917 (Translational Research Oncology Training Program). M.J.L. is a Leukemia Scholar in Clinical Research and a Stephen Birnbaum Translational Research Investigator of the Leukemia and Lymphoma Society. The authors wish to thank Pingfu Fu of the Department of Epidemiology and Biostatistics, Case Western Reserve University School of Medicine, for statistical analyses and Mark Tykocinski for generously providing the plasmid pCTLA-4(h).IgREP7 $\beta$.

\section{References}

1. Goulmy E, Schipper R, Pool J, et al. (1996) Mismatches of minor histocompatibility antigens between HLA-identical donors and recipients and the development of GVHD after bone marrow transplantation. N Engl J Med 334:281

2. Sasazuki T, Juji T, Morishima Y, et al. (1998) Effect of matching HLA class I alleles on clinical outcome after transplantation of hematopoietic stem cells from an unrelated donor. Japan Marrow Donor Program. N Engl J Med 339:1177

3. Cairo M, Wagner J (1997) Placental and/or umbilical cord blood: an alternative source of hematopoietic stem cells for transplantation. Blood 90:4665

4. Hansen J, Gooley T, Martin P, et al. (1998) Bone marrow transplantation from unrelated donors for patients with chronic myeloid leukemia. N Engl J Med 338:962

5. Kernan N, Bartsch G, Ash R, et al. (1993) Analysis of 462 transplantations from unrelated donors facilitated by the National Marrow Donor Program. N Engl J Med 328:593

6. Kurtzberg J, Laughlin M, Graham ML, et al. (1996) Placental blood as a source of hematopoietic stem cells from transplantation into unrelated recipients. N Engl J Med 335:157

7. McGlave P, Shu X, Wen W, et al. (2000) Unrelated donor marrow transplantation for chronic myelogenous leukemia: 9 years' experience of the national marrow donor program. Blood 95:2219

8. Rocha V, Wagner J, Sobocinski K, et al. (2000) GVHD in children who have received a cord-blood or bone marrow transplant from an HLA-identical sibling. N Engl J Med 342:1846

9. Rubinstein P, Carrier C, Scaradavou A, et al. (1998) Outcomes among 562 recipients of placental-blood transplants from unrelated donors. $\mathrm{N}$ Engl J Med 339:1565

10. Sehn L, Alyea E, Weller E, et al. (1999) Comparative outcomes of T-cell-depleted and non-T-cell-depleted allogeneic bone marrow transplantation for CML: impact of donor lymphocyte infusion. J Clin Oncol 17:561

11. Marmont A, Horowitz M, Gale R, et al. (1991) T-cell depletion of HLA-identical transplants in leukemia. Blood 78:2120

12. Champlin R (1990) T-cell depletion for bone marrow transplantation: effects on graft rejection, GVHD, GVL, and survival. Cancer Treatment Res 50:99

13. Lenschow DJ, Walunas TL, Bluestone JA (1996) CD28/B7 system of T cell costimulation. Annu Rev Immunol 14:233

14. Thompson CB, Linsten T, Ledbetter J, et al. (1989) CD28 activation pathway regulates the production of multiple T-cell-derived lymphokines/cytokines. Proc Natl Acad Sci U S A 86:1333

15. Hassan J, O’Neill S, O'Neill L, Pattison U, Reen D (1995) Signaling via CD28 of human naive neonatal T lymphocytes. Clin Exp Immunol 102:192

16. Roncarlo MG, Bigler M, Ciuti E, Martino S, Tovo PA (1994) Immune responses by cord blood cells. Blood Cells 20:573

17. Lanier L, O'Fallon S, Somoza C, et al. (1995) CD80(B7) and CD86(B70) provide similar costimulatory signals for $\mathrm{T}$ cell proliferation, cytokine production and generation of CTL. J Immunol 154:97

18. Linsley P, Brady W, Grosmaire L, Ledbetter J, Damle N (1991) CTLA-4 is a second receptor for the B cell activation antigen B7. J Exp Med 174:561

19. Oosterwegel MA, Greenwald RJ, Mandelbrot DA, Lorsback RB, Sharpe AH (1999) CTLA-4 and T cell activation. Curr Opin Immunol 11:294

20. Walunas TL, Bluestone JA (1998) CTLA-4 regulates tolerance induction and $\mathrm{T}$ cell differentiation in vivo. J Immunol 160:3855

21. Waterhouse P, Penninger JM, Timms E, et al. (1995) Lymphoproliferative disorders with early lethality in mice deficient in CTLA-4. Science 270:985

22. Bluestone JA (1997) Is CTLA-4 a master switch for peripheral T cell tolerance. J Immunol 158:1989

23. Tivol E, Borriello F, Schweitzer A, Lynch W, Bluestone J, Sharpe A (1995) Loss of CTLA-4 leads to massive lymphoproliferation and fatal multiorgan destruction, revealing a critical negative regulatory role of CTLA-4. Immunity 3:541

24. Takahashi T, Tagami T, Yamazaki S, et al. (2000) Immunologic selftolerance maintained by $\mathrm{CD} 25^{+} \mathrm{CD} 4{ }^{+}$regulatory $\mathrm{T}$ cells constitutively expressing CTLA-4. J Exp Med 192:303

25. Karandikar N, Vanderlugt C, Walunas T, Miller S, Bluestone J (1996) CTLA-4: a negative regulator of autoimmune disease. J Exp Med 184:783

26. Karandikar N, Eagar T, Vanderlugt C, Bluestone J, Miller S (2000) CTLA-4 downregulates epitope spreading and mediates remission in relapsing experimental autoimmune encephalomyelitis. J Neuroimmunol 109:173

27. Luhder F, Hoglund P, Allison J, Benoist C, Mathis D (1998) CTLA-4 regulates the unfolding of autoimmune diabetes. J Exp Med 187:427

28. Agarwal K, Czaja A, Jones D, Donaldson P (2000) CTLA-4 gene polymorphisms and susceptibility to type 1 autoimmune hepatitis. Hepatology 31:49

29. Van der Auwera B, Vandewalle C, Schuit F, et al. (1997) CLTA-4 gene polymorphism confers susceptibility to IDDM independently from age and other genetic or immune disease markers. Clin Exp Immunol 110:98

30. Kouki T, Sawai Y, Gardine CA, Fisfalen ME, Alegre ML, DeGroot LJ (2000) CTLA-4 gene polymorphism at position 49 in exon 1 reduced the inhibitory function of CTLA- 4 and contributes to the pathogenesis of Graves disease. J Immunol 165:6606

31. Pullman R, Lukac J, Skerenova M, et al. (1999) CTLA-4 dimorphism in patients with systemic lupus erythematosus. Clin Exp Rheumatol 17:725

32. Blazar B, Taylor A, Panoskaltsis-Mortari A, Sharpe A, Vallera D (1999) Opposing roles of CD28:B7 and CTLA-4:B7 pathways in regulation in vivo alloresponses in murine recipients of $\mathrm{MHC}$ disparate $\mathrm{T}$ cells. J Immunol 162:6368

33. Saito K, Sakurai J, Ohata J, et al. (1998) Involvement of CD40 ligand- 
CD40 and CTLA4-B7 pathways in murine acute GVHD induced by allogeneic T cells lacking CD28. J Immunol 160:4225

34. Yu XZ, Bidwell SJ, Martin PJ, Anasetti C (2000) CD28-specific Ab prevents GVHD in mice. J Immunol 164:4564

35. Yang YF, Zou JP, Wijesuiya R, et al. (1997) Enhanced induction of antitumor T-cell responses by CTLA-4 blockade: the effect is manifested only at the restricted tumor-bearing stages. Cancer Res 57:4036

36. Shrikant P, Khoruts A, Mescher MF (1999) CTLA-4 blockade reverses CD8 + T cell tolerance to tumor by a CD4+ T cell and IL-2 dependent mechanism. Immunity 11:483

37. Mokyr MB, Kalinichenko T, Gorelik Bluestone JA (1998) Realization of the therapeutic potential of CTLA-4 blockade in low-dose chemotherapy-treated tumor-bearing mice. Cancer Res 58:5301

38. Hurwitz AA,Yu TFY, Leach DR, Allison, JP (1998) CTLA-4 blockade synergizes with tumor-derived GMCSF for treatment of an experimental mammary carcinoma. Proc Natl Acad Sci U S A 95:10067

39. van Elsas A, Hurwitz AA, Allison JP (1999) Combination immunotherapy of B16 melanoma using anti-CTLA-4 and GM-CSF-producing vaccines induces rejection of subcutaneous and metastatic tumors accompanied by autoimmune depigmentation. J Exp Med 190:3555

40. Leach DR, Krummel F, Allison JP (1996) Enhancement of antitumor immunity by CTLA-4 blockade. Science 271:1734

41. Kadereit S, Mohammad S, Miller R, et al. (1999) Reduced NFAT1 protein expression in human UCB T lymphocytes. Blood 94:3101

42. Brunschwig EB, Levine E, Trefzer U, Tykocinski ML (1995) GPImodified murine B7-1 and B7-2 retain costimulator function. J Immunol 155:5498

43. Chomczyski P, Sacchi N (1987) Single-step method of RNA isolation by acid guanidinium thiocyanate-phenol-chloroform extraction. Anal Biochem 162:156

44. Zhang Y, Allison JP (1997) Interaction of CTLA-4 with AP50, a clathrin-coated pit adaptor protein. Proc Natl Acad Sci U S A 94:9273

45. Chuang E, Alegre ML, Duckett CS, Noel PJ, Heiden MGV, Thompson CB (1997) Interaction of CTLA-4 with the clathrin-associated protein AP50 results in ligand-independent endocytosis that limits cell surface expression. J Immunol 159:144
46. Linsley PS, Greene JL, Tan P, et al. (1992) Coexpression and functional cooperation of CTLA-4 and CD28 on activated T lymphocytes. J Exp Med 176:1595

47. Khattri R, Auger J, Griffin MD, Sharpe AH, Bluestone JA (1999) Lymphoproliferative disorder in CTLA-4 knockout mice is characterized by CD28-regulated activation of Th2 responses. J Immunol 162:5784

48. Perkins D, Wang Z, Donovan C, et al. (1996) Regulation of CTLA-4 expression during $\mathrm{T}$ cell activation. J Immunol 156:4154

49. Chalmers I, Janossy G, Contreras M, Navarete C (1998) Intracellular cytokine profile of cord and adult blood lymphocytes. Blood 92:11

50. Risdon G, Gaddy J, Stehman FB, Broxmeyer HE (1994) Proliferative and cytotoxic responses of human cord blood T lymphocytes following allogeneic stimulation. Cell Immunol 154:14

51. Risdon G, Gaddy J, Horie M, Broxmeyer H (1995) Alloantigen priming induces a state of unresponsiveness in human UCB T cells. Proc Natl Acad Sci U S A 92:2413

52. Rao A, Luo C, Hogan P (1997) Transcription factors of the NFAT family: regulation and function. Annu Rev Immunol 15:707

53. Finn PW, He H, Wang Y, et al. (1997) Synergistic induction of CTLA-4 expression by costimulation with TCR plus CD28 signals mediated by increased transcription and mRNA stability. J Immunol 158:4074

54. Wekerle T, Kurtz J, Ito H, et al. (2000) Allogeneic bone marrow transplantation with costimulatory blockade induced macrochimerism and tolerance without cytoreductive host treatment. Nature 6:464

55. Guinan EC, Boussiotis VA, Neuberg D, et al. (1999) Transplantation of anergic histoincompatible bone marrow allografts. N Engl J Med 340:1704

56. Alegre ML, Shiels H, Thompson CB, Gajewski TF (1998) Expression and function of CTLA-4 in Th1 and Th2 cells. J Immunol 161:3347

57. Kato T, Nariuchi H (2000) Polarization of naive $\mathrm{CD} 4^{+}$T cells towards the Th1 subset by CTLA-4 costimulation. J Immunol 164:3554

58. Kadereit S, Kozik MM, Junge GR, et al. (2001) Cyclosporin A effects after primary and secondary activation of human umbilical cord blood T lymphocytes. Exp Hematol 29:903 